\title{
Triggers and maintenance of multiple shifts in the state of a natural community
}

\author{
Andrew Rassweiler • Russell J. Schmitt • \\ Sally J. Holbrook
}

Received: 6 November 2009/Accepted: 14 May 2010/Published online: 6 June 2010

(c) The Author(s) 2010. This article is published with open access at Springerlink.com

\begin{abstract}
Ecological communities can undergo sudden and dramatic shifts between alternative persistent community states. Both ecological prediction and natural resource management rely on understanding the mechanisms that trigger such shifts and maintain each state. Differentiating between potential mechanisms is difficult, however, because shifts are often recognized only in hindsight and many occur on such large spatial scales that manipulative experiments to test their causes are difficult or impossible. Here we use an approach that focuses first on identifying changes in environmental factors that could have triggered a given state change, and second on examining whether these changes were sustained (and thus potentially maintained the new state) or transitory (explaining the shift but not its persistence). We use this approach to evaluate a community shift in which a benthic marine species of filter feeding sea cucumber (Pachythyone rubra) suddenly came to dominate subtidal rocky reefs that had previously supported high abundances of macroalgae, persisted for more than a decade, then abruptly declined. We found that a sustained period without large wave events coincided with the shift to sea cucumber dominance, but that the sea cucumbers persisted even after the end of this low wave period, indicating that different mechanisms
\end{abstract}

Communicated by Tony Underwood.

A. Rassweiler $(\bowtie) \cdot$ R. J. Schmitt · S. J. Holbrook

Marine Science Institute, University of California,

Santa Barbara, CA 93106, USA

e-mail: rassweil@lifesci.ucsb.edu

A. Rassweiler · R. J. Schmitt · S. J. Holbrook

Department of Ecology, Evolution and Marine Biology,

University of California, Santa Barbara, CA 93106, USA maintained the new community. Additionally, the period of sea cucumber dominance occurred when their predators were rare, and increases in the abundance of these predators coincided with the end of sea cucumber dominance. These results underscore the complex nature of regime shifts and illustrate that focusing separately on the causes and maintenance of state change can be a productive first step for analyzing these shifts in a range of systems.

Keywords State change - Community dynamics . Predation · Competition · Disturbance

\section{Introduction}

As ecologists have accumulated data on community composition over increasingly long time spans, they have become aware that communities can undergo sudden and dramatic changes in composition, switching into new persistent states. These abrupt changes in community structure, also called regime shifts (Scheffer and Carpenter 2003; Folke et al. 2004), phase shifts (Done 1992) or ecological surprises (Paine et al. 1998), have excited much interest because of their implications both for ecological understanding and for the management of natural systems. Despite intensive study, the mechanisms underlying such shifts are often difficult to determine. A shift may represent a switch between alternative stable states, in which positive feedbacks maintain the new regime even under environmental conditions similar to those prevailing before the change (for examples see Scheffer et al. 2001; Suding et al. 2004; Schroder et al. 2005). Alternatively, the new regime may be maintained by a persistent change in an abiotic or biotic environmental driver. In this second case, positive feedbacks may contribute to the abrupt nature of the 
change, but are not sufficient to maintain the new regime in the absence of continuous environmental forcing.

Two well-documented regime shifts exemplify the different ways in which a shift can be maintained. First, changes in community state within lake systems often represent switches between alternate stable states. When lakes switch between clear and turbid water (Carpenter et al. 1999) or between communities dominated by submerged plants versus floating species (Scheffer et al. 2003), positive feedbacks prevent return to the previous regime even if external forcing such as nutrient and sediment inputs decline to pre-switch levels. Second, in pelagic and nearshore ecosystems off the west coast of North America, dramatic changes in the plankton (McGowan et al. 2003), demersal fish (Holbrook et al. 1997; Brooks et al. 2002) and pelagic fish communities (Chavez et al. 2003) occurred in the late 1970s. Although the details of this regime shift are not fully understood, it is commonly agreed that persistent changes in the climate-including changes in ocean circulation, stratification and temperature-underlie this shift, and that the step-like changes observed in the biological community were the product of nonlinear responses to these new climatic conditions.

Unfortunately, understanding the mechanisms underlying a particular shift poses major challenges. Given high natural variability in many ecosystems, shifts often are only recognized years after they occur, when it becomes clear that the community is not returning to its previous state (deYoung et al. 2004, 2008). For example, brittle star barrens in Southern California were initially presumed to be a transient invertebrate aggregation (Carroll et al. 2000), but ended up persisting for more than a decade. As a result of delays in recognition, data used to document a shift and evaluate potential drivers, if available at all, typically have not been collected for that purpose. Additionally, because shifts are infrequent in many systems, only a small number of separate shifts may be observed, making it difficult to apply existing analytical methods that typically require large amounts of data and many observed shifts (e.g., Ives et al. 2003). Finally, shifts occurring on large spatial scales can be logistically challenging (e.g., Hughes et al. 2007), or even impossible to experimentally reproduce (e.g., deMenocal et al. 2000; Hare and Mantua 2000).

Because formal analysis of the causes underlying ecological state changes often is not possible, some researchers have used a heuristic approach, describing the feedbacks involved without reference to alternative explanations. Here we apply a more structured approach that focuses on identifying potential causes of a shift and determining whether these factors were either persistent, and thus capable of maintaining the new state, or transitory, suggesting that the mechanisms maintaining the new state were different than those that triggered the shift. The first step of this approach is to identify alternative hypotheses for the trigger of an observed change, focusing on factors that would be expected to have a strong influence on the organisms involved. For each of these potential drivers, one can then determine whether they were changing in a direction that could have contributed to the state change at the time when the shift happened. Finally, for each factor that changed in the specified direction, one asks whether that change was sustained for the length of the new state. Although this approach may not show definitively what caused or maintained a change in state, it provides a framework to identify what mechanisms may have been responsible and may often be the only recourse for exploring these underlying mechanisms.

We illustrate the utility of our proposed approach by applying it to changes in ecological state that occurred in the benthic community on rocky reefs at the Channel Islands in Southern California, USA during the past three decades. Our data come from a series of sites at Santa Cruz Island where an abrupt shift occurred in 1987, from a prior state in which the filter-feeding sea cucumber Pachythyone rubra was nearly absent, to a state in which this species dominated. The new regime persisted until 2002 when a second shift occurred, with $P$. rubra densities declining dramatically at all of the sites, remaining relatively low through 2008 (Fig. 1a). Algae show a contrasting pattern, declining in the late 1980s, and remaining low until after 2002 (Fig. 1b). These shifts in community structure are spatially extensive, with beds of $P$. rubra extending in some cases for hundreds of meters, and they have major consequences for the ecological functioning of these reefs. The consequences for primary production are profound, as autotrophs are replaced by heterotrophs, but there are also cascading effects on the whole food chain, with the loss of macroalgae leading to a reduction in micro-crustaceans and in their associated fish predators (Schmitt and Holbrook 1990a, 2007).

Here we first present alternative mechanisms that would be expected to affect $P$. rubra populations, and thus could explain shifts to and from a high $P$. rubra state. We then present time series data on each of these drivers to compare conditions before and after each shift, to address whether any of the potential drivers changed in a direction that could explain the shift, and if so, whether the change in that driver persisted, potentially explaining the maintenance of the new state. This case study provides a framework for studying similarly important shifts in other ecosystems, advancing our ability to predict and understand state shifts more generally.

Alternative hypotheses for community shifts

Below are five mechanisms that could have caused one or both of the state changes that we documented. Because 


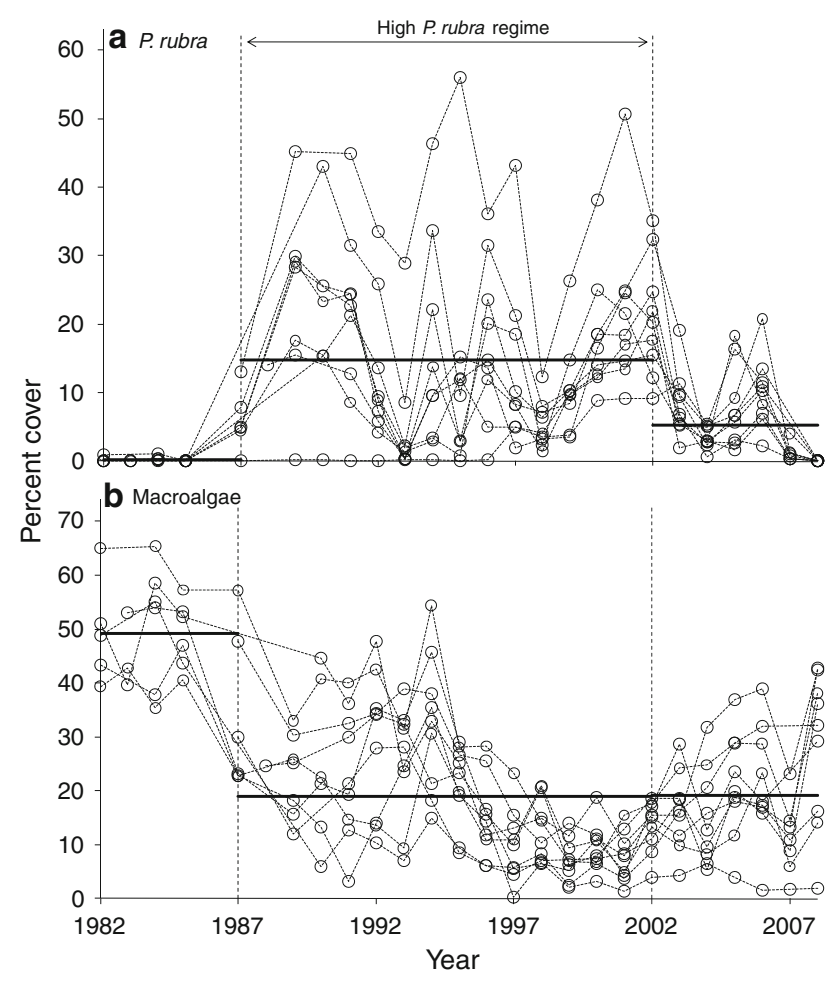

Fig. 1 Percent cover of a the sea cucumber Pachythyone rubra and b macroalgae at sites on the north shore of Santa Cruz Island, California, USA from 1982 to 2007. Circles represent mean cover measured at individual sites (the average of two transects per site per year), dashed lines connect circles representing subsequent observations at the same site, horizontal bars represent average cover within each regime

P. rubra and macroalgae compete strongly for space (Rassweiler 2008) we focused on factors that would be expected to directly affect $P$. rubra populations, macroalgal populations or to alter competitive interactions between the two. In some cases these factors are external to the system (such as wave disturbance), and in other cases they are part of the community (such as grazers) and thus are potentially subject to more complicated feedbacks with P. rubra and macroalgae. No list of alternative hypotheses can be exhaustive; these were chosen because they were the most relevant alternatives given our experience with the system and because the proposed mechanisms have been demonstrated in the literature or through our own experimental work.

\section{Hypothesis 1: change in predation pressure on P. rubra}

A change in predation intensity on $P$. rubra might explain either shift in state. Pachythyone rubra is unpalatable and thus has few predators except the sunflower sea star, Pycnopodia helianthoides and to a much lesser extent the California spiny lobster, Panulirus interruptus (Eckert 1999, 2007). In fact, patterns of abundance of Pycnopodia helianthoides have been hypothesized to explain the distribution of aggregations of Pachythyone rubra, both on a regional scale (tens of kilometers), and on a very local scale (hundreds of meters; Eckert 1999). We use time series data on density of $P$. helianthoides and the biomass of $P$. interruptus to test whether shifts between regimes could have been triggered by changes in predation pressure.

Hypothesis 2: change in grazing pressure on macroalgae

Macroalgae can be reduced by the grazing activity of sea urchins (Paine and Vadas 1969; Graham 2004), which have been suggested to contribute to switches between crustose coralline algae-dominated "barrens" and macroalgaedominated communities (Harrold and Reed 1985; Leinaas and Christie 1996; Konar and Estes 2003). Time series data on urchin abundance reflect the density of actively grazing urchins, allowing us to test whether changes in grazing mortality of macroalgae might explain the observed state changes.

Hypothesis 3: altered light availability for macroalgae due to presence of giant kelp

Increased shading by canopy-forming kelp might have indirectly caused the shift to high $P$. rubra density by inhibiting understory macroalgae. The relative dominance of macroalgae and invertebrates is strongly affected by light availability in many subtidal systems (e.g., Irving and Connell 2002; Miller and Etter 2008). The giant kelp, Macrocystis pyrifera, can reduce light availability under its canopy (Reed and Foster 1984) and has been shown to favor invertebrate dominance on reefs in Southern California (Schmitt and Holbrook 1990b; Arkema et al. 2009). Additionally, abundance of giant kelp can be highly variable though time in this region (e.g., Reed et al. 2008). We examined records of kelp cover to test whether changes in shading due to the density of the kelp canopy could explain the observed regime shifts.

\section{Hypothesis 4: altered nutrient availability}

The shift to sea cucumber dominance might also have been triggered by a change in nutrient availability, in one of two ways. First, because marine macroalgal growth can be limited by nitrogen availability (e.g., Ryther and Dunstan 1971; Fujita et al. 1989) reduced nutrient availability might have decreased algal abundance and thus increased space available for $P$. rubra. Second, increased nutrient availability could have increased phytoplankton abundance, increasing the food supply for $P$. rubra and increasing their population growth rate. Although we do not have access to 
nutrient data for the period when the initial regime shift occurred, temperature records are available and have been shown to correlate well with nitrate availability at other reefs in the Santa Barbara Channel (McPhee-Shaw et al. 2007). We use temperature time series data to estimate changes in nitrate concentration, and test whether changes in nitrate concentration could have triggered shifts in abundance of $P$. rubra.

Hypothesis 5: altered competitive ability of macroalgae: smaller waves

Finally, the shift to a high $P$. rubra regime might have been triggered by environmental conditions that reduced the ability of macroalgae to compete with P. rubra for space. In many benthic reef communities, interactions between algae and invertebrates depend on wave action, which moves algal fronds, abrading or dislodging nearby invertebrates (Coyer et al. 1993; Connell 2003; Box and Mumby 2007). Interactions between $P$. rubra and macroalgae appear to be mediated by waves; in experiments where $P$. rubra were introduced into plots with macroalgae and ones where algae had been removed, $P$. rubra survived in both treatments throughout the calm summer and fall, climbing on top of algae where present. Once winter storms began, however, $P$. rubra were swept away from plots with algae but remained in the cleared plots (Rassweiler 2008). Because negative effects of algae on P. rubra occur only in periods of high wave action, years with few wave events may provide opportunities for P. rubra to become dominant. We use records of wave height to test whether changes in wave action might explain the observed shifts in community state.

\section{Materials and methods}

Data sources: biological data

To evaluate the causes of state change, we used biological data from nine sites on the north shore of Santa Cruz Island, California. Along a 5-km stretch of coastline (centered on $34.05^{\circ} \mathrm{N}, 119.737^{\circ} \mathrm{W}$ ), six replicate sites were chosen in 1982 and three more were added in 1989. These sites were chosen to be similar in depth, slope, exposure and initial benthic community structure (for a description of the sites see Schmitt and Holbrook 1986; Holbrook and Schmitt 1989). Prior to 1989 , not all sites were sampled in each year, but from 1989 onwards each site was sampled annually. At each site there are two fixed 40-m transects, one following the 6-m isobath and one following the 9-m isobath. Each autumn, the percent cover of P. rubra, understory macroalgae (mainly species in the genera
Eisenia, Laurencia, Gelidium, Rhodymenia, Codium and Corallina), sea urchins and $M$. pyrifera was estimated using point contact methods (eight randomly located points were scored per meter per transect). Because of its low density, the sea star $P$. helianthoides was counted in a 2-m-wide swath centered on each transect. To document changes in the abundance of $P$. rubra, macroalgae, sea urchins and $M$. pyrifera, we calculated the average percent cover across all transects sampled in each year. To document changes in the abundance of $P$. helianthoides, we calculated the mean density across all transects sampled in each year.

Data on abundance of the lobster, P. interruptus, were not available from the site level surveys, because lobsters hide during the day and would not appear in visual transects. Instead, we used a regional time series of lobster biomass, which had been generated by fitting a Bayesian size-structured model to a historical time series of catch and effort (McArdle 2008).

Data sources: physical data

Data on water temperature (used to estimate nutrient concentration) and on wave heights were taken from buoys operated by the National Oceanic and Atmospheric Administration (http://www.ndbc.noaa.gov). Because no single buoy operated without interruption between 1982 and 2008, data from three buoys were utilized. The East Santa Barbara buoy (no. 46053) is located nearest to the sites where biological data were collected $(23 \mathrm{~km} \mathrm{NNW}$ of the study sites) and, therefore, water temperatures and wave heights recorded at this buoy were used when available. On days when these data were not available from the East Santa Barbara buoy, data from the Pt. Arguello buoy and Santa Maria buoy (nos. 46023 and 46011, $\sim 135 \mathrm{~km} \mathrm{NW}$ of the monitoring sites) were used to estimate wave height and water temperature in the east channel. Estimates were made based on linear regressions developed from days when all three buoys were operational.

Estimates of dissolved inorganic nitrogen (DIN) concentrations were based on the relationship between temperature and DIN observed on mainland reefs north of our sites ( $~ 30 \mathrm{~km}$ north; McPhee-Shaw et al. 2007). To describe nutrient availability in each year, we calculated median DIN concentration across all days, using 1 October as the cutoff between years, because biological sampling typically occurred near this date. To quantify wave intensity over the same time period, we calculated the number of days when maximum significant wave height was above $3.25 \mathrm{~m}$. We chose $3.25 \mathrm{~m}$ as our definition of a large storm because in a previous experiment the competitive effects of algae on $P$. rubra abundance were only apparent when 
waves rose above this height (Rassweiler 2008). This analysis did not include the summer period of each year (May up to and including September), because summer swells typically come from a southerly direction and the northern shores of the Channel Islands, where our sites are located, are sheltered from these waves.

\section{Data analysis}

Our approach focuses on determining what factors might have triggered a state change, and then asking whether changes in those factors were persistent, potentially explaining the maintenance of the new state, or transient, indicating that a separate mechanism(s) maintained the new state. We can ask both of these questions for the switch into the $P$. rubra-dominated state because we have data from the period when the switch occurred and from an extended period following the switch. We can also address what mechanism triggered the second state change, the switch back to a low P. rubra state, but we have less data for addressing the maintenance of this state because that shift occurred recently.

To determine which of the five hypothesized mechanisms could have triggered each switch, we compared the mean value of the relevant driver for each year in the 5 years prior to the switch to the mean value in the year the switch occurred and the following 4 years. We tested whether the mean driver changed in a direction consistent with the hypothesized mechanism using a one-tailed $t$ test. For DIN we used a two-tailed test, because a change in either direction could potentially have triggered the shift.

In the case of urchins, changes in their density were very patchy within sites, so in addition to analyzing the average densities through time, we were able to address the effect of grazing (and thus potential removal of macroalgae) on P. rubra by analyzing data on a smaller spatial scale. For these analyses we focused on 1989, the year urchin density reached an early peak. We aggregated the transect data in 8-m segments (instead of the site level, as was used for all other analyses), with the cover of organisms in each segment estimated from 64 random points. We compared the cover of $P$. rubra in the $20 \%$ of segments with no urchins to cover in the $20 \%$ of segments with the highest cover of urchins at that time ( $>4 \%$ cover). No statistical tests were done to compare the means, because of potential nonindependence of samples, but the comparison gives a sense of the potential magnitude of any effect of urchins.

For the high P. rubra state we tested whether any of the drivers that potentially triggered this state could have also maintained the state. We examined two periods of similar length (1992-1997 and 1998-2002), during which the high densities of $P$. rubra continued. For each driver that changed at the initial switch, we tested whether it persisted in each of these periods at levels different from those prior to the shift, again using one-tailed $t$ tests. All analyses were performed in SAS (version 9.1; SAS Institute).

\section{Results}

Triggers of the shift to the high P. rubra state

Comparison of conditions immediately before and after the first shift indicates that of the five hypothesized mechanisms, only grazing and waves could have triggered the increase in densities of $P$. rubra. Changes in predation pressure cannot explain the switch because sea stars (Pycnopodia helianthoides) were absent both before and after the regime shift (Fig. 2a) and lobster biomass (Panulirus interruptus) did not change (Fig. 2b). Similarly, increased shading and altered nutrient availability are not possible explanations because the mean percent cover of giant kelp decreased (Fig. 2d) improving growth conditions for understory macroalgae and mean DIN did not change (Fig. 2e) implying no change to growth conditions for macroalgae and for phytoplankton. By contrast, reduced wave action appears to be a likely trigger. In the years leading up to the shift, large waves occurred on average 6.8 days per year. After the shift large waves occurred on only 1.2 days per year, a significant decrease $\left(t_{8}=2.82\right.$, $P=0.016$; Fig. 2f). Grazing pressure also appears at first glance to be a possible trigger for the switch given that urchins were more abundant after the switch than before ( $\left.t_{8}=3.12, P=0.019\right)$. However, the magnitude of the change was relatively small; the cover of urchins shifted from 0 to $1 \%$ (Fig. 2c). To test whether this $1 \%$ change in urchin densities might have led to the large increase in P. rubra, we took advantage of the fact that urchins were patchily distributed within each site. We found that increases of $P$. rubra in areas without urchins were similar to those with urchins, making them an unlikely explanation for the shift. In 1989, when urchins were at their early postshift peak, P. rubra covered $20 \%$ ( $\pm 5.6 \mathrm{SE})$ of the substrate in transect segments with no urchins, only slightly lower than P. rubra's $23 \%$ ( $\pm 4.1 \mathrm{SE})$ mean coverage in the segments with the highest cover of urchins. Therefore, although urchins may have increased the cover of $P$. rubra within some areas, this increase was slight relative to the shift from $\sim 0$ to $>20 \%$ cover that occurred everywhere.

Maintenance of the high $P$. rubra state

Of the two environmental drivers that could have triggered the shift to high sea cucumber abundance, only sea urchins, the less likely trigger, persisted throughout the high $P$. rubra regime. Urchin densities were significantly higher 
Fig. 2 Potential environmental drivers of regime shifts (mean \pm SE) estimated for each 5- to 6-year period: a density of predatory sea stars Pycnopodia helianthoides, b biomass of lobster (Panulirus interruptus), $\mathbf{c}$ percent cover of sea urchins, $\mathbf{d}$ percent cover of Macrocystis pyrifera, e concentration of dissolved inorganic nitrogen $(D I N)$, f frequency of high wave events

during both the 1992-1997 and 1998-2002 periods than prior to the shift $\left(t_{9}=4.57, P=0.003\right.$ and $t_{8}=6.9$, $P=0.001)$. Indeed, urchins continued to increase over this time period, undergoing their most dramatic population growth in 1999, when they reached $11 \%$ cover (Fig. 3).

By contrast, the likely trigger of the shift, low waves, did not persist throughout the regime. In 1992-1997 they were significantly less frequent than in the period prior to the regime shift ( $t_{8}=1.91, P=0.046$ ), but in $1998-2002$ this pattern had been reversed and there were more days with high waves than in the period before the shift (Fig. 4). Although low waves appear to be the initial cause of the state shift, they were not responsible for maintaining high densities of sea cucumbers throughout the new regime.

Causes of the shift out of the high P. rubra state

Of the five hypothesized mechanisms, only the change in the abundance of one predator of sea cucumbers, the sunflower star $P$. helianthoides, can explain their decline. This change was dramatic; sunflower stars suddenly appeared at many sites simultaneously in 2003 (Fig. 5). P. helianthoides density had been zero in the 5 years prior to 2002, and seven per $100 \mathrm{~m}^{2}$ afterwards (a significant increase, $\left.t_{8}=4.088, P=0.007\right)$. This increase coincided with a massive decrease in $P$. rubra density and a modest increase in algal cover. These changes in the sea cucumber and macroalgal populations cannot be explained by changes in the biomass of lobsters (which did not change significantly), grazer density (which declined slightly), nutrient availability (which did not change significantly), kelp shading (which increased) or frequency of large waves (which decreased).

\section{Discussion}

The shifts between macroalgae-dominated communities and sea cucumber-dominated communities at Santa Cruz Island provide a dramatic example of state change with which we illustrate a general post hoc approach to studying mechanisms responsible for regime shifts. This approach focuses on identifying drivers that might have triggered a shift and then asking whether those same drivers could

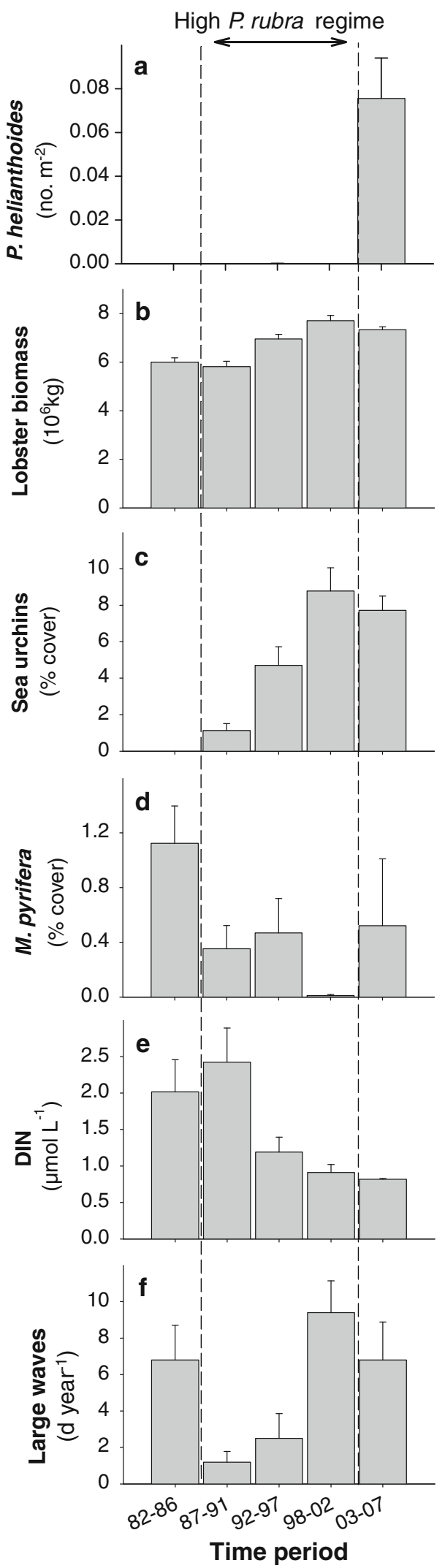




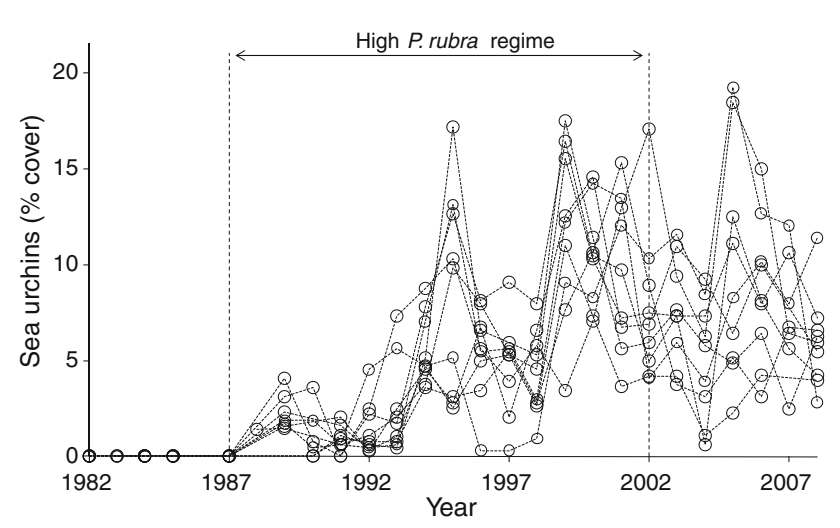

Fig. 3 Cover of sea urchins from 1982 to 2008 at sites on the north shore of Santa Cruz Island. Circles represent mean percent cover measured at individual sites $(n=2$ transects per site per year)

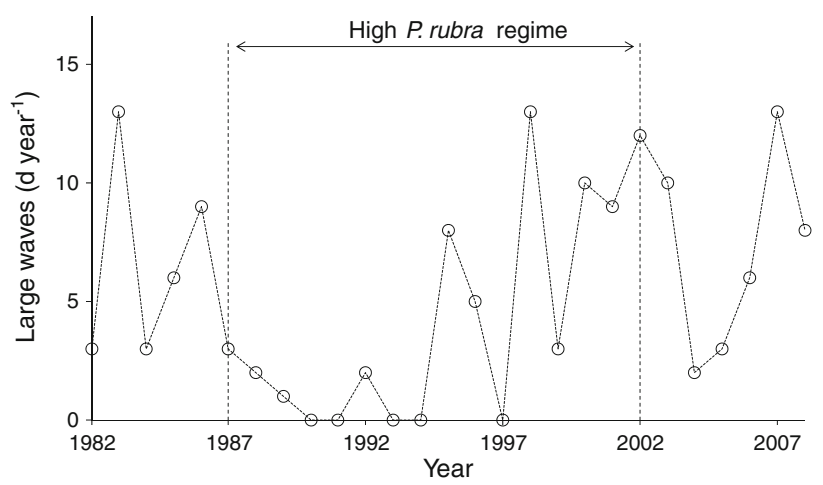

Fig. 4 Frequency of winter storms from 1982 to 2008, measured as the number of days per year when maximum significant wave height was greater then $3.25 \mathrm{~m}$ at the east Santa Barbara buoy

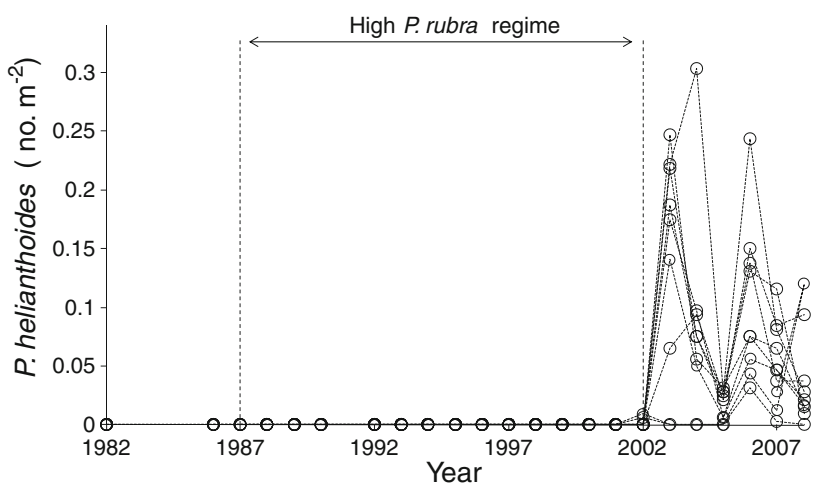

Fig. 5 Density of the predatory sea star $P$. helianthoides at sites on the north shore of Santa Cruz Island from 1982 to 2008. Circles represent mean density measured at individual sites $(n=2$ transects per site per year)

have maintained the new state. It can provide insight about the underlying mechanisms, even in situations where analyses must be retrospective and few separate shifts have been observed. In this case, our approach is most useful for analyzing the sea cucumber-dominated state, because we have data to evaluate both the initiation and maintenance of this state. We show that the most likely explanation for the change in state was reduced frequency in wave events, which rendered macroalgae less capable of competing for space with $P$. rubra, but we also show that low waves cannot explain the maintenance of the subsequent community state.

A previous 9 month long experimental manipulation of P. rubra and macroalgae (Rassweiler 2008) demonstrated how strong their interactions can be. Cover of $P$. rubra declined by more than $50 \%$ in the presence of a natural density of macroalgae, with these declines occurring only after winter storms arrived. Cover of macroalgae declined by more than $30 \%$ in the presence of $P$. rubra densities within the range of those observed in the high $P$. rubra state. The strength of the negative effects observed in these experiments suggests that reduced storm frequency would have removed a strong negative effect on $P$. rubra, potentially explaining their increase. It also indicates that the rapid decline in algae could easily be explained by the increased competitive effects of $P$. rubra, thus fully accounting for the shift in density.

Determining what mechanism(s) maintains a state is typically more difficult than identifying the cause of a shift, in part because the changes in community structure associated with the state shift may set up positive feedbacks which reinforce the new community. In such cases a temporary change in one factor may trigger a shift in community state, but positive feedbacks allow the new state to persist even after the triggering factor returns to its previous levels. Potentially strong positive feedbacks are present in the $P$. rubra-macroalgae system. $P$. rubra compete with macroalgae for space but they also consume algal spores from the water column just above the reef substrate, reducing algal settlement rates by more than $50 \%$ in beds of $P$. rubra relative to adjacent experimental clearings. Spatially explicit models of these interactions indicate that once $P$. rubra reaches high density, this intense predation on algal spores may prevent algae from increasing in density, preventing the return of the macroalgae-dominated community (Rassweiler 2008). This web of interactions is a form of intra-guild predation, which has been linked to alternative stable states in a number of systems (e.g., Holt and Polis 1997; Diehl and Feissel 2001; Price and Morin 2004). Other positive feedbacks are also possible. For example, Barkai (1991) showed that a related species of sea cucumber has greater ability to endure strong wave action when in a dense bed. If positive feedbacks can lead to alternative stable states in our system, the maintenance of the high $P$. rubra regime after the return of high waves requires no additional explanation.

A limitation of our approach, however, is that it cannot disentangle the roles of internal feedbacks, external drivers 
and other factors in the maintenance of a state. For example, sea urchin density increased substantially towards the end of the high $P$. rubra regime, during the same period when large waves were returning and increasing the competitive ability of macroalgae. Grazing by sea urchins during this period likely helped delay the return of a macroalgae-dominated, low $P$. rubra state, but it is difficult to determine the relative importance of higher grazing pressure versus positive feedbacks.

Several experimental and observational methods have been proposed to test whether alternative regimes are maintained by internal feedbacks as opposed to continuous external forcing. For example, in some systems it can be shown that alternative communities develop from different initial community states, even under the same environmental conditions (e.g., Chase 2003a; Scheffer et al. 2003) or that a short term perturbation can cause a persistent change in community state (Paine and Trimble 2004; Petraitis et al. 2009). But for many regime shifts, such as those occurring between vegetated and arid states (deMenocal et al. 2000), between forests and grasslands (Dublin et al. 1990; Sternberg 2001) or between different large-scale marine regimes (Hare and Mantua 2000; Reid et al. 2001), experimental manipulations are difficult and expensive to perform at the relevant spatial scale. In systems like this, evidence for the causes of state change must be gleaned from observational data.

One potential approach is to compare the fits of different models to time series data. This can involve comparing linear and nonlinear models (Hsieh et al. 2005), quantifying metrics of stability for different states (Ives et al. 2003), or comparing the fits of models with and without alterative stable states (Carpenter and Pace 1997; Liermann and Hilborn 1997). However, these approaches share the drawback of requiring long time series of high resolution data, ideally including many switches in state. Longer time series of ecological data are crucial for detecting regime shifts (deYoung et al. 2008; Andersen et al. 2009), but because shifts occur with a frequency of decades or longer in many systems (e.g., Chavez et al. 2003), these methods can require centuries of data.

Another difficulty with many approaches to analyzing regime shifts is that they implicitly assume that a community shifts between only two regimes. In ecosystems where more than one state change has been observed, there are often more than two possible regimes (e.g., Hare and Mantua 2000; Bond et al. 2003; Suding et al. 2004; Norström et al. 2009). In our case study, if one focused only on $P$. rubra, there might appear to be only two states: prior to 1987 the sea cucumbers were nearly absent, from 1987 to 2002 they were very abundant, and after 2002 they returned to their low density state. However, when the three states are viewed in a multi-species context, the third regime is clearly not equivalent to the first. It consists of different species and is maintained by a new mechanismpredation.

This third state was initiated by the sudden arrival of the predatory sea star, $P$. helianthoides, a mobile and voracious predator, with well-established potential to decimate echinoderm populations (Mauzey et al. 1968; Pearse and Hines 1987). Sea stars were first observed at relatively high densities and large sizes-35 $\mathrm{cm}$ or more across-suggesting that they immigrated to these sites, either from deeper water or from the western end of the island where they have been persistently observed (Eckert 2007).

The role of sea stars in the initiation and maintenance of the third state illustrates that an interaction between multiple environmental drivers was necessary to trigger the initial shift into the high P. rubra phase. The absence of predators alone was not sufficient to cause a shift, as is apparent in the early 1980s, when P. rubra remained rare even though predators were absent. Similarly, it is unlikely that low waves could have triggered a shift into the high density state if $P$. helianthoides had been present, because the sea stars provide strong top down control of $P$. rubra. Indeed, it has been suggested that such interactions between multiple drivers may be a general feature of shifts between persistent community states (Paine et al. 1998; Scheffer and Carpenter 2003; Chase 2003b; Ling et al. 2009).

Understanding the mechanisms underlying ecological state change can greatly advance the conservation and management of these systems. If the shifts represent alternative stable states, they are typically less reversible (e.g., Carpenter et al. 1999), and therefore managers must consider how to avoid shifts to less preferred states (King 1995; Folke et al. 2004). Understanding what maintains each state may also indicate how best to induce a desired shift, either through manipulation of external factors such as nutrient input or livestock density (e.g., Carpenter et al. 1999; Suding et al. 2004; Bestelmeyer 2006), or through direct manipulation of the natural community, for example by removing or adding organisms (e.g., McClanahan et al. 1999).

Our results underscore the complex nature of state changes. Different mechanisms may underlie the initiation, maintenance and end of a regime and interactions between multiple drivers may be necessary to trigger shifts in state. Despite the importance of understanding the causes of state shifts, there is no commonly accepted method for evaluating potential causes. Here we focused on whether the cause of a shift can also explain the maintenance of the new state, and demonstrated the utility of this approach in a system where few shifts in state have been observed. We remain limited, however, in our ability to determine the relative degree to which the altered community state is maintained by positive feedbacks versus other factors. 
Improving methods for evaluating these alternatives, particularly when experiments are not practical and few regime shifts have been observed, is an important and ongoing challenge for modern ecology.

Acknowledgments We thank K. Seydel and many divers for their work collecting the biological data, B. Kinlan for data on lobster biomass, D. Reed, R. Nisbet, S. Lester, T. Underwood and two anonymous reviewers for comments and advice on the manuscript and support from National Science Foundation grants OCE 9982105 and OCE 0620276.

Open Access This article is distributed under the terms of the Creative Commons Attribution Noncommercial License which permits any noncommercial use, distribution, and reproduction in any medium, provided the original author(s) and source are credited.

\section{References}

Andersen T, Carstensen J, Hernandez-Garcia E, Duarte CM (2009) Ecological thresholds and regime shifts: approaches to identification. Trends Ecol Evol 24:49-57

Arkema KK, Reed DC, Schroeter SC (2009) Direct and indirect effects of giant kelp determine benthic community structure and dynamics. Ecology 90(11):3126-3137

Barkai A (1991) The effect of water movement on the distribution and interaction of three holothurian species on the South African west coast. J Exp Mar Biol Ecol 153:241-254

Bestelmeyer BT (2006) Threshold concepts and their use in rangeland management and restoration: the good, the bad, and the insidious. Restor Ecol 14:325-329

Bond NA, Overland JE, Spillane M, Stabeno P (2003) Recent shifts in the state of the North Pacific. Geophys Res Lett 30:2183

Box SJ, Mumby PJ (2007) Effect of macroalgal competition on growth and survival of juvenile Caribbean corals. Mar Ecol Prog Ser 342:139-149

Brooks AJ, Schmitt RJ, Holbrook SJ (2002) Declines in regional fish populations: have species responded similarly to environmental change? Mar Freshwater Res 53:189-198

Carpenter SR, Pace ML (1997) Dystrophy and eutrophy in lake ecosystems: implications of fluctuating inputs. Oikos 78:3-14

Carpenter SR, Ludwig D, Brock WA (1999) Management of eutrophication for lakes subject to potentially irreversible change. Ecol Appl 9:751-771

Carroll JC, Engle JM, Coyer JA, Ambrose RF (2000) Long-term changes and species interactions in a sea urchin-dominated community at Anacapa Island, California. In: Proceedings of the 5fth California Islands symposium, pp 370-378

Chase JM (2003a) Experimental evidence for alternative stable equilibria in a benthic pond food web. Ecol Lett 6:733-741

Chase JM (2003b) Community assembly: when should history matter? Oecologia 136:489-498

Chavez FP, Ryan J, Lluch-Cota SE, Niquen CM (2003) From anchovies to sardines and back: multidecadal change in the Pacific Ocean. Science 299:217-221

Connell SD (2003) Negative effects overpower the positive of kelp to exclude invertebrates from the understory community. Oecologia 137:97-103

Coyer JA, Ambrose RF, Engle JM, Carroll JC (1993) Interactions between corals and algae on a temperature zone rocky reef: mediation by sea urchins. J Exp Mar Biol Ecol 167:21-37
deMenocal P, Ortiz J, Guilderson T, Adkins J, Sarnthein M, Baker L, Yarusinsky M (2000) Abrupt onset and termination of the African Humid Period: rapid climate responses to gradual insolation forcing. Quat Sci Rev 19:347-361

deYoung B, Harris R, Alheit J, Beaugrand G, Mantua N, Shannon L (2004) Detecting regime shifts in the ocean: data considerations. Prog Oceanogr 60:143-164

deYoung B, Barange M, Beaugrand G, Harris R, Perry RI, Scheffer M, Werner F (2008) Regime shifts in marine ecosystems: detection, prediction and management. Trends Ecol Evol 23:209-402

Diehl S, Feissel M (2001) Intraguild prey suffer from enrichment of their resources: a microcosm experiment with ciliates. Ecology 82:2977-2983

Done TJ (1992) Phase shifts in coral reef communities and their ecological significance. Hydrobiologia 247:121-132

Dublin HT, Sinclair ARE, McGlade J (1990) Elephants and fire as causes of multiple stable states in the Serengeti-Mara woodlands. J Anim Ecol 59:1147-1164

Eckert GL (1999) Consequences of diverse reproductive strategies in marine invertebrates. $\mathrm{PhD}$ dissertation, University of California, Santa Barbara

Eckert GL (2007) Spatial patchiness in the sea cucumber Pachythyone rubra in the California Channel Islands. J Exp Mar Biol Ecol 348:121-132

Folke C, Carpenter S, Walker B, Scheffer M, Elmqvist T, Gunderson L, Holling CS (2004) Regime shifts, resilience, and biodiversity in ecosystem management. Annu Rev Ecol Syst 35:557-581

Fujita RM, Wheeler PA, Edwards RL (1989) Assessment of macroalgal nitrogen limitation in a seasonal upwelling region. Mar Ecol Prog Ser 53:293-303

Graham MH (2004) Effects of local deforestation on the diversity and structure of southern California giant kelp forest food webs. Ecosystems 7:341-357

Hare SR, Mantua NJ (2000) Empirical evidence for North Pacific regime shifts in 1977 and 1989. Prog Oceanogr 47:103-145

Harrold C, Reed DC (1985) Food availability, sea urchin grazing, and kelp forest community structure. Ecology 66:1160-1169

Holbrook SJ, Schmitt RJ (1989) Resource overlap, prey dynamics, and the strength of competition. Ecology 70:1943-1953

Holbrook SJ, Schmitt RJ, Stephens JS (1997) Changes in an assemblage of temperate reef fishes associated with a climate shift. Ecol Appl 7:1299-1310

Holt RD, Polis GA (1997) A theoretical framework for intraguild predation. Am Nat 149:745-764

Hsieh CH, Glaser SM, Lucas AJ, Sugihara G (2005) Distinguishing random environmental fluctuations from ecological catastrophes for the North Pacific Ocean. Nature 435:336-340

Hughes TP, Rodriuges MJ, Bellwood DR, Ceccarelli D, HoeghGuldberg O, McCook L, Moltschaniwskyj N, Pratchett MS, Steneck RS, Willis B (2007) Phase shifts, herbivory, and the resilience of coral reefs to climate change. Curr Biol 17:1-6

Irving AD, Connell SD (2002) Sedimentation and light penetration interact to maintain heterogeneity of subtidal habitats: algal versus invertebrate dominated assemblages. Mar Ecol Prog Ser 245:83-91

Ives AR, Dennis B, Cottingham KL, Carpenter SR (2003) Estimating community stability and ecological interactions from time-series data. Ecol Monogr 73:301-330

King A (1995) Avoiding ecological surprise-lessons from longstanding communities. Acad Manag Rev 20:961-985

Konar B, Estes JA (2003) The stability of boundary regions between kelp beds and deforested areas. Ecology 84:174-185

Leinaas HP, Christie H (1996) Effects of removing sea urchins (Strongylocentrotus droebachiensis): stability of the barren state 
and succession of kelp forest recovery in the east. Atlantic 105:524-536

Liermann M, Hilborn R (1997) Depensation in fish stocks: a hierarchic Bayesian meta-analysis. Can J Fish Aquat Sci 54:1976-1984

Ling SD, Johnson CR, Frusher SD, Ridgway KR (2009) Overfishing reduces resilience of kelp beds to climate-driven catastrophic phase shift. Proc Natl Acad Sci USA 106:22341-22345

Mauzey KP, Birkeland C, Dayton PK (1968) Feeding behavior of asteroids and escape responses of their prey in the Puget Sound region. Ecology 49:603

McArdle DA (2008) Integrating ecology and history to understand historical marine population dynamics: a case study of the California spiny lobster. $\mathrm{PhD}$ dissertation, University of California, Santa Barbara

McClanahan TR, Hendrick V, Rodrigues MJ, Polunin NVC (1999) Varying responses of herbivorous and invertebrate-feeding fishes to macroalgal reduction on a coral reef. Coral Reefs 18:195-203

McGowan JA, Bograd SJ, Lynn RJ, Miller AJ (2003) The biological response to the 1977 regime shift in the California current. Deep Sea Res 50:2567-2582

McPhee-Shaw EE, Siegel DA, Washburn L, Brzezinski MA, Jones JL, Leydecker A, Melack J (2007) Mechanisms for nutrient delivery to the inner shelf: observations from the Santa Barbara Channel. Limnol Oceanogr 52:1748-1766

Miller RJ, Etter RJ (2008) Shading facilitates sessile invertebrate dominance in the rocky subtidal Gulf of Maine. Ecology 89:452462

Norström AV, Nyström M, Lokrantz J, Folke C (2009) Alternative states on coral reefs: beyond coral-macroalgal phase shifts. Mar Ecol Prog Ser 376:295-306

Paine RT, Trimble AC (2004) Abrupt community change on a rocky shore-biological mechanisms contributing to the potential formation of an alternative state. Ecol Lett 7:441-445

Paine RT, Vadas RL (1969) Effects of grazing by sea urchins, Strongylocentrotus spp., on benthic algal populations. Limnol Oceanogr 14:710-719

Paine RT, Tegner MJ, Johnson EA (1998) Compounded perturbations yield ecological surprises. Ecosystems 1:535-545

Pearse JS, Hines AH (1987) Long-term population dynamics of sea urchins in a central California kelp forest: rare recruitment and rapid decline. Mar Ecol Prog Ser 39:275-283

Petraitis PS, Methratta ET, Rhile EC, Vidargas NA, Dudgeon SR (2009) Experimental confirmation of multiple community states in a marine ecosystem. Oecologia 161:139-148
Price JE, Morin PJ (2004) Colonization history determines alternate community states in a food web of intraguild predators. Ecology 85:1017-1028

Rassweiler A (2008) Mechanisms underlying community shifts in the Santa Barbara Channel. PhD dissertation, University of California, Santa Barbara

Reed DC, Foster MS (1984) The effects of canopy shading on algal recruitment and growth in a giant kelp forest. Ecology 65:937948

Reed DC, Rassweiler A, Arkema KK (2008) Biomass rather than growth rate determines variation in net primary production by giant kelp. Ecology 89:2493-2505

Reid PC, Borges MF, Svendsen E (2001) A regime shift in the North Sea circa 1988 linked to changes in the North Sea horse mackerel fishery. Fish Res 50:163-171

Ryther JH, Dunstan WM (1971) Nitrogen, phosphorus, and eutrophication in the coastal marine environment. Science 171:10081013

Scheffer M, Carpenter SR (2003) Catastrophic regime shifts in ecosystems: linking theory to observation. Trends Ecol Evol 18:648-656

Scheffer M, Carpenter SR, Foley JA, Walker B (2001) Catastrophic shifts in ecosystems. Nature 413:591-596

Scheffer M, Szabo S, Gragnani A, Van Nes EH, Rinaldi S, Kautsky N, Norberg J, Roijackers RMM, Franken RJM (2003) Floating plant dominance as a stable state. Proc Natl Acad Sci USA 100:4040-4045

Schmitt RJ, Holbrook SJ (1986) Seasonally fluctuating resources and temporal variability of interspecific competition. Oecologia 69:1-11

Schmitt RJ, Holbrook SJ (1990a) Population responses of surfperch released from competition. Ecology 71:1653-1665

Schmitt RJ, Holbrook SJ (1990b) Contrasting effects of giant kelp on dynamics of surfperch populations. Oecologia 84:419-429

Schmitt RJ, Holbrook SJ (2007) Predicting the magnitude of temporal variation in young-of-year class strength of surfperch. Raffles Bull Zool S14:161-166

Schroder A, Persson L, De Roos AM (2005) Direct experimental evidence for alternative stable states: a review. Oikos 110:3-19

Sternberg LSL (2001) Savanna-forest hysteresis in the tropics. Global Ecol Biogeogr 10:369-378

Suding KN, Gross KL, Houseman GR (2004) Alternative states and positive feedbacks in restoration ecology. Trends Ecol Evol 19:46-53 